\title{
BMJ Open Multilevel influences on resilient healthcare in six countries: an international comparative study protocol
}

\author{
Janet E Anderson, ${ }^{1,2}$ Karina Aase (D) , ${ }^{2}$ Roland Bal, ${ }^{3}$ Mathilde Bourrier, ${ }^{4}$ \\ Jeffrey Braithwaite (D) , Kazue Nakajima, ${ }^{6}$ Siri Wiig, ${ }^{2}$ Veslemøy Guise (D) ${ }^{2}$
}

To cite: Anderson JE, Aase K, Bal R, et al. Multilevel influences on resilient healthcare in six countries: an international comparative study protocol. BMJ Open 2020;10:e039158. doi:10.1136/ bmjopen-2020-039158

- Prepublication history for this paper is available online. To view these files, please visit the journal online (http://dx.doi. org/10.1136/bmjopen-2020039158).

Received 06 April 2020 Revised 31 August 2020 Accepted 18 November 2020

Check for updates

(C) Author(s) (or their employer(s)) 2020. Re-use permitted under CC BY-NC. No commercial re-use. See rights and permissions. Published by BMJ.

For numbered affiliations see end of article.

Correspondence to

Dr Veslemøy Guise;

veslemoy.guise@uis.no

\section{ABSTRACT}

Introduction Resilient healthcare (RHC) is an emerging area of theory and applied research to understand how healthcare organisations cope with the dynamic, variable and demanding environments in which they operate, based on insights from complexity and systems theory. Understanding adaptive capacity has been a focus of RHC studies. Previous studies clearly show why adaptations are necessary and document the successful adaptive actions taken by clinicians. To our knowledge, however, no studies have thus far compared RHC across different teams and countries. There are gaps in the research knowledge related to the multilevel nature of resilience across healthcare systems and the team-based nature of adaptive capacity.

This cross-country comparative study therefore aims to add knowledge of how resilience is enabled in diverse healthcare systems by examining adaptive capacity in hospital teams in six countries. The study will identify how team, organisational and national healthcare system factors support or hinder the ability of teams to adapt to variability and change. Findings from this study are anticipated to provide insights to inform the design of RHC systems by considering how macro-level and meso-level structures support adaptive capacity at the micro-level, and to develop guidance for organisations and policymakers.

Methods and analysis The study will employ a multiple comparative case study design of teams nested within hospitals, in turn embedded within six countries: Australia, Japan, the Netherlands, Norway, Switzerland and the UK. The design will be based on the Adaptive Teams Framework placing adaptive teams at the centre of the healthcare system with layers of environmental, organisational and system level factors shaping adaptive capacity. In each of the six countries, a focused mapping of the macro-level features of the healthcare system will be undertaken by using documentary sources and interviews with key informants operating at the macro-level.

A sampling framework will be developed to select two hospitals in each country to ensure variability based on size, location and teaching status. Four teams will be selected in each hospital-one each of a structural, hybrid, responsive and coordinating team. A total of eight teams will be studied in each country, creating a total sample of 48 teams. Data collection methods will be observations,
Strengths and limitations of this study

- First international cross-country, multilevel comparative study of resilience in healthcare.

- An in-depth exploration of adaptive capacity in 48 hospital teams in six countries.

- Development of team adaptive capacity theory grounded in rich data.

- Limited number of hospitals included in each country could reduce generalisability.

- Language differences and health system variations may challenge cross-country comparison.

interviews and document analysis. Within-case analysis will be conducted according to a standardised template using a combination of deductive and inductive qualitative coding, and cross-case analysis will be conducted drawing on the Qualitative Comparative Analysis framework. Ethics and dissemination The overall Resilience in Healthcare research programme of which this study is a part has been granted ethical approval by the Norwegian Centre for Research Data (Ref. No. 8643334 and Ref. No. 478838). Ethical approval will also be sought in each country involved in the study according to their respective regulatory procedures. Country-specific reports of study outcomes will be produced for dissemination online. A collection of case study summaries will be made freely available, translated into multiple languages. Brief policy communications will be produced to inform policymakers and regulators about the study results and to facilitate translation into practice. Academic dissemination will occur through publication in journals specialising in health services research. Findings will be presented at academic policy and practitioner conferences, including the annual RHC Network meeting and other healthcare quality and safety conferences. Presentations at practitioner and academic conferences will include workshops to translate the findings into practice and influence quality and safety programmes internationally.

\section{INTRODUCTION}

Resilient healthcare (RHC) is an emerging area of theory and (applied) research to understand how healthcare organisations 
cope with the dynamic, variable and demanding environments in which they operate based on insights from complexity and systems theory. RHC can be defined as 'the capacity to adapt to challenges and changes at different system levels, to maintain high-quality care'. ${ }^{1}$ Over approximately a decade, multidisciplinary researchers interested in studying how performance emerges in nonlinear complex systems such as healthcare have advanced theory and identified the key features of RHC systems. The evolution of this thinking can be traced in a series of edited books ${ }^{2-4}$ from which the following four key concepts can be distilled.

First, resilience is conceptualised as a characteristic of systems and processes rather than individuals. ${ }^{5}$ This perspective is not focused on individual psychological resilience to stressful events, but on how organisational processes can support adaptation to deal with problems and challenges. Second, complex and open systems in healthcare experience variability in the conditions under which clinical work occurs. ${ }^{6}$ For example, patient flow and workload fluctuate, staff shortages and equipment breakdowns occur, patients vary in their understanding of, and willingness to consent to procedures, and clinical complexity is usually not predictable. Third, as a result of variable demands, clinical processes must adapt to unforeseen challenges so that high-quality care can still be delivered. ${ }^{7}$ Fourth, resilience is proposed to rely on the ability to anticipate developments, respond to problems, monitor processes and learn from experience. ${ }^{8}$

Many RHC studies contain detailed descriptions of healthcare work which clearly show why adaptations are necessary, and document successful adaptive actions taken by clinicians. ${ }^{9-12}$ Recently however, researchers have begun to apply these ideas to improving quality, by asking how insights into complexity and the need for adaptive capacity can inform quality improvement processes. ${ }^{13}$ Further examples can be found in a recent book on delivering RHC. ${ }^{14}$ However, the evidence base is still developing and there are gaps in the research knowledge. ${ }^{15-18}$ Although adaptive capacity is thought to be provided by the activities of anticipating, responding, monitoring and learning, ${ }^{8}$ we still do not know how these activities can be strengthened, whether there are other components of adaptive capacity, how resilience is enabled, and how adaptive capacity can be nurtured and supported in organisations.

Furthermore, there have been no studies to our knowledge that have compared RHC in different countries and so the influence of domestic healthcare structures and regulatory regimes on adaptive capacity is not known. Although cross-country comparative studies are generally not common in health services research, those that exist have added to our understanding of how macrocontextual factors shape, constrain and facilitate clinical work. ${ }^{19-22}$ These studies have also illuminated different ways to organise clinical work and how these relate to outcomes. Such multilevel investigations often aim to tease out how the national organisation of healthcare systems, organisational and team factors interact to influence performance. They thus enlarge our knowledge of the possibilities regarding the organisation of healthcare. For RHC, such studies are especially important given the early stage of development of the field. For adaptive capacity to be enabled and supported, team structures and processes, organisational factors, and a country's healthcare policy and regulatory system need to allow resilience to emerge when it is required in response to a challenge or change in the environment. ${ }^{23}{ }^{24}$ However, we do not currently know enough about adaptive capacity at multiple system levels to really understand how to support resilience. ${ }^{16}$

A second gap in our knowledge about RHC relates to teamwork. Most RHC studies have investigated adaptations made by individual clinicians, but most clinical and organisational work in hospitals is carried out by teams, which are the smallest functional units in hospitals. The few RHC studies that have examined teams and teamwork $^{25-27}$ are limited because they have not considered how teams are defined and structured, what their functions are or the different types of teams that are found in healthcare. There have been studies of adaptive teams in other domains, ${ }^{28}$ but healthcare teams have unique characteristics. Teams differ depending on their goals, tasks, structure, membership and location. Healthcare teamwork is complex and multilayered and is characterised by a network of multiteam systems interacting to accomplish collective goals. ${ }^{29} 30$ Teamwork in multiteam systems usually features interprofessional interaction, multiple handovers, professional hierarchies and the need to coordinate progress towards multiple goals across time and locations. These factors determine their need for adaptive capacity, the types of challenges that necessitate adaptation and flexibility, and the types of adaptations that are feasible. Hence, understanding adaptive capacity requires a more sophisticated analysis and understanding of teams than has been applied in most RHC studies.

Teamwork research in healthcare has focused on areas with similar characteristics to teams studied in other domains such as aviation and disaster response. Consequently, most teamwork research in healthcare has studied areas such as surgery and emergency care ${ }^{31}$ which have time limited well-defined tasks and stable team membership, even though these areas represent only a small proportion of healthcare work. Current theories are therefore not representative of many healthcare teams and are not comprehensive. Recent research ${ }^{32}$ has provided a schema of four main types of teams in hospitals. These are:

1. Structural teams. These are usually ward-based teams whose members routinely work together and comprise different disciplines, such as medicine, nursing, physiotherapy, coordinating their actions to care for patients.

2. Hybrid teams. Hybrid teams have some permanent members and some rotating members. An example is teams on short stay acute medical units, which com- 
monly have a permanent nursing team and a rotating medical team.

3. Responsive teams. These teams react to time-limited emergencies such as cardiac arrests or incidents of aggression and violence or provide specialist expertise such as trauma, haemorrhage and other acute care teams. Such teams are often experienced at working together and have well-defined aims and methods of working.

4. Coordinating teams. These teams facilitate decisionmaking and workflow. Their work can span organisational units, such as bed management teams who coordinate patient flow across a hospital, and multidisciplinary teams who coordinate patient care within an organisational unit.

Different types of teams experience different challenges requiring them to adapt in different ways to maintain effective performance. ${ }^{32}$ It is therefore essential to conduct research that is sensitive to team type, structure and context. This study will build on the already established evidence base on RHC in complex and dynamic hospital settings by expanding it with a team-based, multilevel perspective.

\section{Aims and objectives}

This international comparative study is part of the Resilience in Healthcare $(\mathrm{RiH})$ research programme led by the Norwegian Centre for Resilience in Healthcare (SHARE), comprising five work packages to advance the theory and practice of RHC. ${ }^{33}$ The aim of the crosscountry comparative study described here is to investigate how adaptive capacity in hospital teams is influenced by team, organisational and healthcare system factors. It aims to answer the question of how multilevel system factors interact to support or hinder adaptive capacity in different types of hospital teams and how this leads to performance variability. The study will take place in hospitals in the following six countries: Australia, Japan, the Netherlands, Norway, Switzerland and the UK. The study objectives are to:

1. Conduct a macro-level analysis of the healthcare systems in each country using documentary sources and interviews with key informants. The analysis will be based on mapping healthcare system contextual factors in each country such as funding and access, patient rights, regulatory framework, accreditation and monitoring, information availability and resources available.

2. Create a sampling framework based on team types in hospitals that can be used to select and recruit teams in each country.

3. Collect in-depth qualitative data using an agreed template in each of the selected empirical settings in the six countries. This will involve interviews (micro, meso, macro) and observations of clinical work and managerial processes to identify how adaptive capacity is enabled or inhibited in each team and organisation.

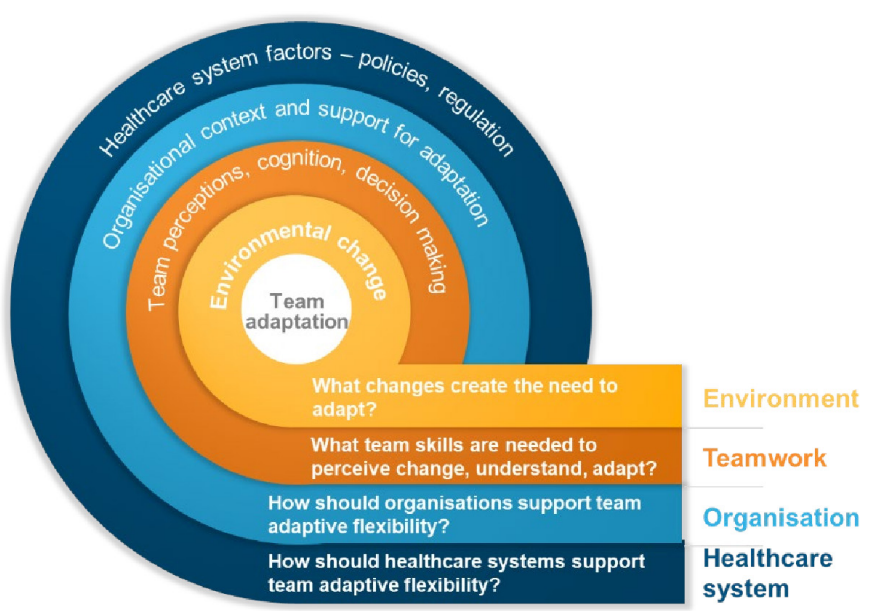

Figure 1 Adaptive teams framework and research questions.

4. Conduct a within-case analysis in each country according to a joint protocol to determine adaptive capacities at micro-level, meso-level and macro-level in the selected empirical settings in each country. The within-case analysis will result in six country-specific reports in English to enable cross-country comparison.

5. Conduct a comparative cross-case analysis to synthesise and compare findings across the six country reports using a common conceptual framework, aiming to identify a wider range of adaptive capacities than in previous research, as well as how adaptation is shaped by organisational, cultural, economic and regulatory factors in different countries.

6. Develop guidance for policymakers, managers and practitioners for operationalising and implementing RHC in different countries and organisational contexts.

\section{DESIGN}

The study will have a multiple comparative case study design $^{34}$ of teams nested within hospitals, embedded within countries. The design will be based on the Adaptive Teams Framework, which has been developed to guide data collection and analysis in this study and is shown in figure 1. This framework shows adaptive teams at the centre of the healthcare system with layers of environmental, organisational and system level factors shaping adaptive capacity. These layers of influence, which will be identified and articulated in the study, could support or hinder adaptive capacity. The new knowledge to be created by the study is highlighted by the research questions at each level of the framework. First, we want to understand the environmental pressures or challenges that require adaptation and delineate whether and how different teams are sensitive to these changes. Second, the teamwork skills that are required to perceive changes and respond appropriately by adapting will be identified. Third, we will explore how the organisational context supports or hinders adaptive capacity, and fourth, how 
the organisation of the healthcare system in each country supports or hinders adaptive capacity. The framework will be reviewed, modified and extended with the empirical findings of the study, thus contributing to the theoretical and practical advancement of RHC theory. The study will be carried out between 2020 and 2023.

\section{METHODS AND ANALYSIS}

\section{Phase 1: mapping of country characteristics and sampling}

In each country, a focused mapping of the macro-level features of the healthcare system will be undertaken to understand the broad organisational and regulatory structures of the hospitals. The mapping will be based on documentary sources and interviews with up to five key informants operating at the macro-level of the system. The framework for mapping the healthcare system characteristics will focus on the regulatory processes in each country since they set out the framework within which organisational decision-making and behaviour take place. Purposive interviews with informants such as regulatory inspectors, leaders of quality improvement organisations, and healthcare organisation directors will be undertaken to review the emergent mapping and verify its accuracy.

Researchers from all the selected countries are active members of the Resilient Health Care Network (RHCN), an international community of practice for advancing the principles and practice of RHC. The study collaboration was founded on shared research interests and approaches to the study of healthcare systems. The six participating countries were selected because they are of contrasting sizes and geographical characteristics, and have differently structured healthcare systems, but share in common a high standard of living, as well as highly comparable levels of health expenditure as a percentage of gross domestic product. Table 1 shows preliminary data for each country, which will be developed and expanded during the study.

A sampling framework will be developed to select two hospitals in each country, ensuring variability in size, location and teaching status. Within each hospital, four teams will be selected to represent each of the structural, hybrid, responsive and coordinating types of teams. Eight teams will therefore be studied in each country, creating a total sample of 48 teams. Table 2 details the team sampling. A detailed description of team types will be developed to assist selection in each country, based on in-depth discussion with the international research team. Differences in healthcare structures between countries will require in-depth discussion to understand and clearly define team types and the criteria for team selection.

\section{Phase 2: within-country case studies}

The aim of the case studies is to understand in-depth how effective adaptive teams can be designed and supported. To do this, the study will identify the environmental pressures that create the need for adaptation, how teamwork skills contribute to adaptive capacity in each type of team, and how it is supported or hindered by organisational and healthcare system factors. The types of teams studied include those operating at the micro-level (structural and hybrid), and the meso-level (responsive and coordinating), generating data about micro-level and meso-level adaptation. In-depth qualitative data will be collected over a period of 3 months in each hospital using the following methods:

\section{General observations and documentary analysis}

Observations will initially be broad and aim to map the team context, including types of patients, key tasks, processes, demands, challenges, performance measures, team membership and management structures. Organisational documents will be subject to content analysis to identify the context of teamwork. Data will be thematically analysed to comprehensively describe the organisational context for teamwork.

\section{Observations of adaptive teamwork}

Tasks requiring team communication and coordination such as ward rounds, briefings, meetings and handover, will be identified during step 1 (above), and observed multiple times to account for differences due to such factors as time of day, change of staff and patient numbers. The focus at this stage will be on understanding how work is structured and organised and how teams coordinate their activities. Researchers will then shadow different team members to observe their activities and discuss their work to clarify their aims, problems encountered, solutions found and any other contextual factors that require clarification. Data will be captured using detailed field notes entered into a data collection template. The template will be structured to facilitate documentation of key theoretical and conceptual resilience components inspired by some of our recent work ${ }^{15182335}$ and the system activities underpinning adaptive capacity. These include for example, demand-capacity misalignments, adaptations, outcomes, anticipating, monitoring, coordinating, responding and learning. Observers will be trained in using this template and team discussions during the data collection process will assist with problem solving, interpretation and reliability across cases. The field notes will be analysed thematically and described qualitatively to allow understanding of the subtleties and nuances of adaptive teamwork.

\section{Interviews}

A sample of four to five staff in each team and four to five staff at managerial levels will be interviewed. A sampling frame will be developed to ensure that a representative sample of professions and levels of seniority is interviewed. A topic guide will be used for semistructured interviews to probe staff perceptions of teamwork capacities. Topic guides will be tailored to the context of each team. Example topics, based on recent conceptual work in the $\mathrm{RiH}$ programme ${ }^{135}$ and previous experience researching $\mathrm{RiH},{ }^{23} 36$ include: 
Table 1 Overview of characteristics of participating countries

\begin{tabular}{|c|c|c|c|c|}
\hline Country & Organisation and structure & $\begin{array}{l}\text { Funding system and } \\
\text { healthcare expenditure }\end{array}$ & $\begin{array}{l}\text { Regulation of quality and } \\
\text { safety }\end{array}$ & $\begin{array}{l}\text { Population and } \\
\text { country size }\end{array}$ \\
\hline Australia & $\begin{array}{l}\text { Universal health coverage } \\
\text { through Medicare } \\
\text { Federated structure with } \\
\text { agreements between } \\
\text { the Commonwealth } \\
\text { (Australian) Government } \\
\text { and the states and } \\
\text { territories }^{44}\end{array}$ & $\begin{array}{l}\text { Taxpayer funded for } \\
\text { two-thirds of all care; } \\
\text { one-third is paid } \\
\text { through private health } \\
\text { insurance or out-of- } \\
\text { pocket expenditure } \\
\text { Healthcare } \\
\text { expenditure at } 9.3 \% \\
\text { of GDP } \\
\text { Government/ } \\
\text { compulsory spending } \\
67.4 \% \text { of total health } \\
\text { expenditure }\end{array}$ & $\begin{array}{l}\text { Regulation and agencies } \\
\text { split across the Federal } \\
\text { Government (eg, the } \\
\text { Australian Commission } \\
\text { on Safety and Quality } \\
\text { in Health Care) and the } \\
\text { States and Territories (eg, } \\
\text { the Clinical Excellence } \\
\text { Commission in New } \\
\text { South Wales). }{ }^{44}\end{array}$ & $\begin{array}{l}\text { Population: } 25.37 \\
\text { million } \\
\text { Land area: } 7.69 \\
\text { million } \mathrm{km}^{2} \\
\text { Inhabitants per } \\
\mathrm{km}^{2}: 3.3^{46}\end{array}$ \\
\hline Netherlands & $\begin{array}{l}\text { Universal health coverage } \\
\text { through mandatory } \\
\text { insurance. Decentralised, } \\
\text { 'regulated competition' } \\
\text { system with private } \\
\text { insurers and providers }{ }^{50}\end{array}$ & $\begin{array}{l}\text { Mixed system of } \\
\text { insurance and } \\
\text { taxation-based } \\
\text { financing } \\
\text { Healthcare } \\
\text { expenditure at } ~ 9.9 \% \\
\text { of GDP } \\
\text { Government/ } \\
\text { compulsory spending } \\
82.7 \% \text { of total health } \\
\text { expenditure } 45\end{array}$ & $\begin{array}{l}\text { National Health Institute } \\
\text { responsible for setting } \\
\text { standards; quality and } \\
\text { safety supervised by } \\
\text { Health and Youth Care } \\
\text { Inspectorate. }\end{array}$ & $\begin{array}{l}\text { Population: } 17.33 \\
\text { million } \\
\text { Land area: } 41873 \\
\text { km² } \\
\text { Inhabitants per } \\
\text { km }^{2}: 414^{46}\end{array}$ \\
\hline Norway & $\begin{array}{l}\text { Semidecentralised system, } \\
\text { parliament as decision- } \\
\text { making body; state } \\
\text { ownership of hospitals } \\
\text { administered by four } \\
\text { Regional Health Authorities } \\
\text { The Norwegian Board } \\
\text { of Health Supervision } \\
\text { is a national regulatory } \\
\text { body, organised under } \\
\text { the Ministry of Health and } \\
\text { Care Services; county } \\
\text { governors at the regional } \\
\text { level oversee services } \\
\text { within primary and } \\
\text { specialised healthcare }\end{array}$ & $\begin{array}{l}\text { Tax-based system, } \\
\text { limited out-of-pocket } \\
\text { payment } \\
\text { Healthcare } \\
\text { expenditure at } \\
\sim 10.5 \% \text { of GDP } \\
\text { Government/ } \\
\text { compulsory spending } \\
\text { 85.4\% of total health } \\
\text { expenditure }\end{array}$ & $\begin{array}{l}\text { Comprehensive legislation } \\
\text { regarding child welfare, } \\
\text { health and social services: } \\
\text { requirements for quality } \\
\text { of services } \\
\text { regulations for authorised } \\
\text { healthcare personnel } \\
\text { service user rights } \\
\text { Supervision applies to } \\
\text { all statutory services } \\
\text { (municipalities, private } \\
\text { businesses, publicly owned } \\
\text { hospitals, etc). }{ }^{51}\end{array}$ & 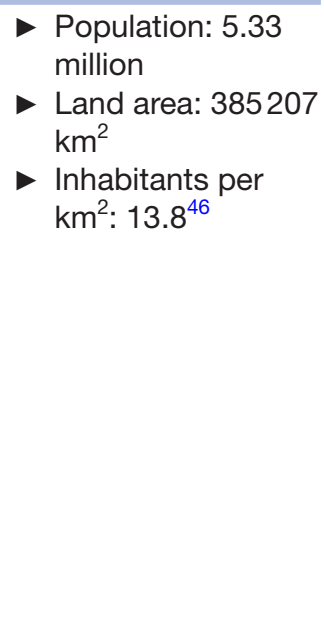 \\
\hline
\end{tabular}




\begin{tabular}{|c|c|c|c|c|}
\hline Country & Organisation and structure & $\begin{array}{l}\text { Funding system and } \\
\text { healthcare expenditure }\end{array}$ & $\begin{array}{l}\text { Regulation of quality and } \\
\text { safety }\end{array}$ & $\begin{array}{l}\text { Population and } \\
\text { country size }\end{array}$ \\
\hline
\end{tabular}

CQC, Care Quality Commission; GDP, gross domestic product.

- Perceptions of the quality of teamwork, including communication, collaboration, learning and inclusion of the patient's perspective by the team.

- Variability experienced in processes and performance.

- Local adjustments of procedures to meet changing demands.

- Individual and team adaptations.

- Cognitive, behavioural, and procedural strategies for managing variability and change.

- Interactions with external actors such as regulators, industry representatives and insurers.

- Activities that enable teams to adapt, such as ability to anticipate, respond, monitor and learn.
Interviews will also be an opportunity to clarify observational data and ask further questions about individual perceptions and experiences. Interviews will be audio recorded, transcribed and analysed thematically to identify the key factors that influence team adaptation and their mechanisms.

Data will be analysed in each country according to a standardised template. In previous work the CARE model ${ }^{5}$ has been used for conceptualising adaptation as a response to changes encountered in the healthcare environment that originate in a mismatch between demand and capacity. The model has since been expanded to include factors that stimulate adaptation and processes

Table 2 Overview of proposed team sampling framework

\begin{tabular}{llll}
\hline Team types & Example teams & $\begin{array}{l}\text { Hospital A- } \\
\text { large teaching } \\
\text { hospital }\end{array}$ & $\begin{array}{l}\text { Hospital B-small } \\
\text { non-teaching } \\
\text { hospital }\end{array}$ \\
\hline Structural & $\begin{array}{l}\text { Ward team caring for paediatric or elderly patients; co-located, stable } \\
\text { membership }\end{array}$ & 1 & 1 \\
\hline Hybrid & $\begin{array}{l}\text { Acute Admissions Unit (short stay unit) for patients referred from emergency } \\
\text { department; combination of stable and rotating membership }\end{array}$ & 1 & 1 \\
Responsive & $\begin{array}{l}\text { Emergency response team for patients experiencing cardiac arrest; diabetes } \\
\text { team responding to inpatients with diabetes; membership may vary but the } \\
\text { team responds to well-defined needs }\end{array}$ & 1 \\
Coordinating & $\begin{array}{l}\text { Multidisciplinary team which meets regularly to discuss and plan the care of } \\
\text { specific patients, as patients with cancer or patients in rehabilitation ward; } \\
\text { membership may vary but involves coordination across organisational units }\end{array}$ & 1 \\
&
\end{tabular}


through which adaptations occur. ${ }^{37}$ The original and adapted CARE models will be used deductively to code concepts such as environmental changes, demand, capacity and adaptation. Additionally, a new framework for defining and operationalising adaptive capacity will be used to guide data analysis in addition to other recent conceptual work. ${ }^{18} 23$ The Integrated Resilience Attributes Framework ${ }^{35}$ defines the types of activities that support adaptation at different scales of a system. For example, learning is required for system resilience, but different learning actions are required depending on whether adaptation is occurring by readjusting processes, reorganising resources or reconfiguring how resources are produced in a system. Using this framework together with the previously described models will facilitate a finegrained analysis of healthcare activities and ensure that the analysis is theoretically coherent. New factors not accounted for by the models and framework will also be identified inductively.

All researchers will discuss and review emerging results from the analysis so that insights can be shared across countries, increasing the reliability of the analysis. This will ensure comparability between the case studies and increase the rigour of the process. Case study reports will be produced in each country, written in English and structured according to an agreed template.

\section{Phase 3: cross-country comparative analysis and guidance}

A cross-case comparative analysis will be conducted to synthesise and compare findings across the six countries to identify how adaptation at the team level is shaped, constrained and facilitated by team, organisational and healthcare system factors. The qualitative analysis will be based on identifying explanatory mechanisms, comparing concepts across cases, refining concepts, and exploring relationships and patterns. The analysis will generate an account of the multiple influences enabling or hindering team adaptive capacity. Although cross-case analysis is challenging, we will use the Qualitative Comparative Analysis method (QCA), ${ }^{38}$ which was developed specifically to facilitate comparison between case studies. QCA provides both an approach and suggested techniques for summarising data, building explanatory models and visualising results of the comparison. This approach can consider the roles and outcomes of multiple causal factors, which will be a feature of the data generated in this study. The cross-case comparison will also be used to identify guidance about how adaptive capacity in healthcare teams will be enabled based on in-depth analysis of the multiple situational and structural influences on team-adaptive capacity.

\section{Effect of the COVID-19 pandemic on data collection}

The continuing effect of the pandemic on healthcare systems worldwide means that it is uncertain when researchers will be able to collect data in person in hospital settings. In many countries, activity that involves risk to researchers is restricted by universities, ethics committees and healthcare organisations, unless absolutely necessary. It is not clear when these restrictions might be lifted and so contingency plans for completing this study have been developed. If necessary, interviews will be carried out before observations, thereby postponing the observation phase to a time when clinical access might again be possible. In this case, interview findings will inform how the observations can be focused on areas requiring further exploration. If observations are still not possible at a later time, we will focus on conducting further individual interviews, alongside group interviews and focus group interviews, with a larger more heterogeneous sample to probe experiences and perceptions of teamwork in more depth. In this case, the results from the initial round of interviews will inform the development of topic guides for a second round of interviews.

The pandemic has required health services to respond quickly to an uncertain and fast developing crisis in the absence of knowledge and experience about the virus. Adaptive responses by frontline clinicians have been vitally important in the overall response and can inform our understanding of adaptation and how it emerged and was supported or hindered. This will be important in planning for and supporting resilient systems in the future. As more information emerges about how healthcare systems responded, we will include questions about responses to COVID-19 in the interview topic guides.

\section{Research team coordination}

The study will involve a large international team of researchers. Regular opportunities for communication and coordination will be arranged, including regular online meetings with the whole team to discuss overall progress and solve problems, ad hoc meetings with selected members to discuss and clarify relevant concerns, and annual face-to-face meetings of the whole team in Norway to share progress, findings and plan activities. Other ad hoc meetings may also be possible at conferences such as the annual RHCN meeting.

\section{Patient and public involvement}

Patient and public involvement (PPI) representatives were involved in the development of the proposal for the overall RiH research programme, ${ }^{33}$ of which this study protocol is a key component. The $\mathrm{RiH}$ research programme furthermore has a patient and citizen representative as co-chair of its international Expert Advisory Board, who has been involved in the project development and has contributed to key aspects of its design. The RiH research programme also has a dedicated patient and stakeholder involvement (PSI) work package, which aims to systematically involve patients and key stakeholders in multiple ways across the programme. The key outcome for the PSI work package is to develop and test a conceptual model for how PSI in RiH can be understood and improved. For the international comparative study, local PPI representatives or PPI panels in each of the six countries will be consulted during the planning and 
conduct of the study. Patients and other stakeholders will also be involved in overall public engagement activities and in translating research into practice in several local languages and cultural contexts. The entire RiH research project is oriented around quality as the outcome of RHC. ${ }^{1}$ Developing better methods for involving patients and stakeholders in $\mathrm{RiH}$, while improving the overall quality of healthcare systems, will benefit patients as recipients of healthcare services.

\section{ETHICS AND DISSEMINATION}

The overall $\mathrm{RiH}$ research programme has been granted ethical approval by the Norwegian Centre for Research Data (Ref. No. 8643334 and Ref. No. 478838). Ethical approval for this international study will also be sought in due course in each country as required by each country's internal research regulatory procedures. Raw data will not be transferred internationally. Individual country case reports of the findings in each country will form the basis of the cross-case comparison and will contain only illustrative examples and anonymised quotations from the raw data. Anonymised data only will be reported in all outputs.

A detailed report of the study outcomes will be produced for dissemination on the international research partner websites. Examples of organisational and regulatory support for adaptive capacity will be identified to enable learning from success. A collection of case study summaries will be compiled and made freely available on the Centre for Resilience in Healthcare (www.uis.no/share) website. These outputs will also be translated into the language of each participating country, to be shared on research partners' websites. Brief policy communications will be produced to inform policymakers and regulators about the results of the study and to facilitate translation into practice.

Academic dissemination will occur through publication in journals specialising in health services research. Findings will be presented at healthcare conferences, including the annual RHCN meeting and other quality and safety conferences. Presentations at practitioner and academic conferences will include workshops to translate the findings into practice and influence quality and safety programmes internationally.

\section{DISCUSSION}

This cross-country comparative study aims to increase knowledge about how resilience is enabled in healthcare systems by examining the adaptive capacity of selected hospital teams in six countries. It will identify how team skills, organisational and national healthcare system factors support or hinder the ability of teams to adapt to variability and changes. The study's findings are anticipated to provide insights into how the design of RHC systems should consider the ways in which macro-level and meso-level structures support team adaptive capacity at the micro-level. The study will produce evidence about how this can be done and will develop guidance for organisations and policymakers.

A focus of much RHC research has been the identification of relatively static policies and procedures that can be unhelpful to clinicians and staff as they seek to cope with the dynamic nature of healthcare work. ${ }^{12}$ For example, Work-As-Imagined is a core RHC concept that focuses attention on how policies do not fit the reality of practice and so act to hinder rather than support clinical work. ${ }^{39}$ However, governmental frameworks should also be enabling, and this study will investigate the question of whether and how such macro-frameworks can be helpful in supporting adaptive capacity. ${ }^{23} 4041$ Moreover, there is an unresolved question about how much adaptation is beneficial. Badly designed systems may require constant adaptation as clinicians attempt to compensate for problems that could be prevented by good design, ${ }^{5}$ and it may be possible that constant adaptation creates additional problems in clinical work. ${ }^{42} 43$

The study is focused on teams as the key resilience mechanism in hospital organisations. Teamwork is known to be difficult in healthcare due to constantly changing team membership, interprofessional differences in education, culture, and expectations, perceived and actual power hierarchies and power differentials, and the episodic nature of teamwork. ${ }^{31}$ Moreover, teams are varied and often not clearly defined. Individuals are likely to work in multiple different teams. ${ }^{32}$ For example, ward nurses may belong to a nursing team, a multidisciplinary team of doctors, nurses and allied health professionals, and a coordinating team such as a bed management team. In this study, we focus on four basic team types identified in previous research, thus ensuring consistency of team definitions across case study countries and providing a theoretical rationale for sampling. This will also expand the evidence base about teamwork in healthcare, which has focused mostly on stable teams with well-defined, timelimited tasks, such as surgery and trauma medicine.

The study will extend the theory of RHC. Most RHC studies have focused on the micro-level and used a descriptive approach to understand how adaptation facilitates the delivery of care. ${ }^{16}$ This study will pose causal questions about how adaptive capacity can be supported and aligned across multiple system levels. It is not possible to conduct an experimental trial to answer such causal questions, but multiple case study designs are commonly used to answer similar questions that are not suited for experimental designs. The multicase study design ${ }^{34}$ will enable comparison between different types of teams, organisations and healthcare systems, the identification of relationships and patterns in the data, and lead to theory generation and greater understanding of how adaptive capacity can be supported in healthcare teams.

The study forms part of a larger research programme designed to advance the theory and practice of RHC by developing theory and methods, studying the role of patients, implementing and evaluating interventions to 
increase resilience, and supporting collaborative learning about RHC. ${ }^{33}$ Although implementing interventions is not the purpose of the current study, intervention testing will be part of the overall work of the SHARE Centre and in the Norwegian part of the RiH programme. The results from this multinational study will inform this future work.

\section{Author affiliations}

${ }^{1}$ School of Health Sciences, City, University of London, London, UK

${ }^{2}$ SHARE-Centre for Resilience in Healthcare, Faculty of Health Sciences, University of Stavanger, Stavanger, Norway

${ }^{3}$ School of Health Policy \& Management, Erasmus University Rotterdam, Rotterdam, South Holland, The Netherlands

${ }^{4}$ Department of Sociology, University of Geneva, Geneva, Switzerland

${ }^{5}$ Centre for Healthcare Resilience and Implementation Science, Australian Institute of Health Innovation, Macquarie University, Sydney, New South Wales, Australia ${ }^{6}$ Department of Clinical Quality Management, Osaka University Hospital, Osaka, Japan

Acknowledgements We want to thank the reviewers for their insightful comments on an earlier draft of this manuscript.

Contributors JEA is the principal investigator of the work package featuring the international comparison, drafted the original manuscript, and contributed to revisions and additions to the manuscript. KA, SW and VG contributed with substantial intellectual content in the study design, drafted parts of the original manuscript and contributed to the revision of the manuscript. RB, MB, JB and $\mathrm{KN}$ contributed to the study design, drafted parts of the original manuscript and contributed to manuscript revisions. All authors approved the final version of the manuscript.

Funding The RiH research programme has received funding from the Research Council of Norway under the FRIPRO Toppforsk programme, grant agreement no 275 367. The University of Stavanger, Norway, the Norwegian University of Science and Technology in Gjøvik, and the Norwegian Air Ambulance support the programme with in-kind funding.

Competing interests None declared.

Patient and public involvement Patients and/or the public were involved in the design, or conduct, or reporting, or dissemination plans of this research. Refer to the Methods section for further details.

Patient consent for publication Not required.

Provenance and peer review Not commissioned; externally peer reviewed.

Open access This is an open access article distributed in accordance with the Creative Commons Attribution Non Commercial (CC BY-NC 4.0) license, which permits others to distribute, remix, adapt, build upon this work non-commercially, and license their derivative works on different terms, provided the original work is properly cited, appropriate credit is given, any changes made indicated, and the use is non-commercial. See: http://creativecommons.org/licenses/by-nc/4.0/.

\section{ORCID iDs}

Karina Aase http://orcid.org/0000-0002-5363-5152

Jeffrey Braithwaite http://orcid.org/0000-0003-0296-4957

Veslemøy Guise http://orcid.org/0000-0002-9124-1664

\section{REFERENCES}

1 Wiig S, Aase K, Billett S, et al. Defining the boundaries and operational concepts of resilience in the resilience in healthcare research program. BMC Health Serv Res 2020;20:330.

2 Hollnagel E, Braithwaite J, Wears RL, eds. Resilient Health Care. Ashgate: Farnham, 2013.

3 Wears RL, Hollnagel E, Braithwaite J, eds. Resilient Health Care Volume 2: The Resilience of Everyday Clinical Work. Ashgate Publishing: Farnham, 2015.

4 Braithwaite J, Wears RL, Hollnagel E, eds. Resilient Health Care Volume 3: Reconciling Work-as-Imagined and Work-as-Done. Boca Raton, FL: CRC Press, 2016.

5 Anderson JE, Ross AJ, Back J, et al. Implementing resilience engineering for healthcare quality improvement using the care model: a feasibility study protocol. Pilot Feasibility Stud 2016;2:61.
6 Braithwaite J, Wears RL, Hollnagel E. Resilient health care: turning patient safety on its head. Int J Qual Health Care 2015;27:418-20.

7 Hollnagel E. Safety-I and Safety-II: the past and future of safety management. Boca Raton, FL: CRC press, 2018.

8 Hollnagel E. Safety-ll in practice: developing the resilience potentials. Abingdon: Routledge, 2017.

9 Patterson MD, Wears RL. Resilience and precarious success. Reliab Eng Syst Saf 2015;141:45-53.

10 Sujan M, Spurgeon P, Cooke M. The role of dynamic trade-offs in creating safety-A qualitative study of handover across care boundaries in emergency care. Reliab Eng Syst Saf 2015;141:54-62.

11 Wachs P, Saurin TA, Righi AW, et al. Resilience skills as emergent phenomena: a study of emergency departments in Brazil and the United States. Appl Ergon 2016;56:227-37.

12 Back J, Ross AJ, Duncan MD, et al. Emergency department escalation in theory and practice: a mixed-methods study using a model of organizational resilience. Ann Emerg Med 2017;70:659-71.

13 Anderson JE, Ross AJ, Back J, et al. Resilience engineering as a quality improvement method. In: Wiig S, Fahlbruch B, eds. Exploring Resilience - A Scientific Journey from Practice to Theory. Cham: Springer Open, 2019: 25-32.

14 Hollnagel E, Braithwaite J, Wears RL, eds. Delivering Resilient Healthcare. Abingdon: Routledge, 2019.

15 Righi AW, Saurin TA, Wachs P. A systematic literature review of resilience engineering: research areas and a research agenda proposal. Reliab Eng Syst Saf 2015;141:142-52.

16 Berg SH, Akerjordet K, Ekstedt M, et al. Methodological strategies in resilient health care studies: an integrative review. Saf Sci 2018;110:300-12.

17 Berg SH, Aase K. Resilient characteristics as described in empirical studies on health care. In: Wiig S, Fahlbruch B, eds. Exploring Resilience - A Scientific Journey from Practice to Theory. Cham: Springer Open, 2019: 79-89.

18 Wiig S, Fahlbruch B, eds. Exploring Resilience. A Scientific Journey from Practice to Theory. Cham: Springer Open, 2019.

19 Wiig S, Aase K, von Plessen C, et al. Talking about quality: exploring how 'quality' is conceptualized in European hospitals and healthcare systems. BMC Health Serv Res 2014;14:478.

20 Burnett S, Mendel P, Nunes F, et al. Using institutional theory to analyse Hospital responses to external demands for finance and quality in five European countries. $J$ Health Serv Res Policy 2016;21:109-17.

21 Anderson JE, Robert G, Nunes F, et al. Translating research on quality improvement in five European countries into a reflective guide for hospital leaders: the 'QUASER Hospital Guide'. Int J Qual Health Care 2019;31:G87-96.

22 Karltun A, Sanne JM, Aase K, et al. Knowledge management infrastructure to support quality improvement: a qualitative study of maternity services in four European hospitals. Health Policy 2020;124:205-15.

23 Wiig S, Aase K, Bal R. Reflexive spaces: Leveraging resilience into healthcare regulation and management. J Patient Saf 2020. doi:10.1097/PTS.0000000000000658. [Epub ahead of print: 31 Jan 2020].

24 Leistikow I, Bal RA. Resilience and regulation, an odd couple? Consequences of Safety-II on governmental regulation of healthcare quality. BMJ Qual Saf 2020;29:1.10-2.

25 Jeffcott SA, Ibrahim JE, Cameron PA. Resilience in healthcare and clinical handover. Qual Saf Health Care 2009;18:256-60.

26 Furniss D, Back J, Blandford A, et al. A resilience markers framework for small teams. Reliab Eng Syst Saf 2011;96:2-10.

27 Wallenburg I, Weggelaar AM, Bal R. Walking the tightrope: how rebels "do" quality of care in healthcare organizations. $J$ Health Organ Manag 2019;33:869-83.

28 van der Beek D, Schraagen JM. Adapter: analysing and developing adaptability and performance in teams to enhance resilience. Reliab Eng Syst Saf 2015;141:33-44.

29 Shuffler ML, Jiménez-Rodríguez M, Kramer WS. The science of multiteam systems: a review and future research agenda. Small Group Research 2015;46:659-99.

30 Anderson JE, Ross AJ, Lim R, et al. Nursing teamwork in the care of older people: a mixed methods study. Appl Ergon 2019;80:119-29.

31 Lavelle M, Reedy GB, Cross S, et al. An evidence based framework for the temporal observational analysis of teamwork in healthcare settings. Appl Ergon 2020;82:102915.

32 Lavelle M, Darzi A, Anderson J. Adaptations in teamworking practice: the role of formal and informal processes. Presented at the Resilient HealthCare Net Annual Meeting; August 26-28, 2019.

33 Aase K, Guise V, Billett S, et al. Resilience in healthcare (RiH): a longitudinal research programme protocol. BMJ Open 2020;10:e038779. 
34 Yin RK. Case study research design and methods. Third edition. Thousand Oaks, CA: SAGE Publications, 2003.

35 Anderson JE, Ross AJ, Macrae C, et al. Defining adaptive capacity in healthcare: a new framework for researching resilient performance. Appl Ergon 2020;87:10311.

36 Anderson JE, Ross AJ, Back J, et al. Beyond 'find and fix': improving quality and safety through resilient healthcare systems. Int J Qual Health Care 2020;32:204-11.

37 Watt A, Jun GT, Waterson P. Resilience in the blood transfusion process: Everyday and long-term adaptations to 'normal' work. Saf Sci 2019;120:498-506.

38 Rihoux B, Lobe $\mathrm{B}$. The case for qualitative comparative analysis (QCA): Adding leverage for thick cross-case comparison. In: Byrne D Ragin C, eds. The SAGE Handbook of case-based methods. London: SAGE Publications, 2009: 222-42.

39 Clay-Williams R, Hounsgaard J, Hollnagel E. Where the rubber meets the road: using FRAM to align work-as-imagined with work-as-done when implementing clinical guidelines. Implement Sci 2015;10:125.

40 Macrae C. Reconciling regulation and resilience in healthcare. In: Hollangel E, Braithwaite J, Wears R, eds. Resilient health care. Boca Raton, FL: Ashgate, 2013: 111-23.

41 Øyri SF, Wiig S. Regulation and resilience at the macro-level healthcare system - a literature review. In: Proceedings of the 29th European safety and reliability conference (ESREL). 2019 September 22-26. Hannover, Germany: Research Publishing Services, 2019: 1373-81. ISBN: 978-981-11-2724-3.

42 Wears RL, Hettinger AZ. The tragedy of adaptability. Ann Emerg Med 2014;63:338-9.

43 Amalberti R, Vincent $C$. Managing risk in hazardous conditions: improvisation is not enough. BMJ Qual Saf 2020;29:60-3.

44 Braithwaite J, Mannion J, Matsuyama J, Shekelle J, Whittaker J, Al-Adawi J, , , , , , , , , ed. Healthcare systems: future predictions for global care. Boca Raton, FI: Taylor and Francis, 2019.

45 OECD. Health spending (indicator). Available: https://data.oecd.org/ healthres/health-spending.htm [Accessed 01 Dec 2020].
46 United Nations Department of Economic and Social Affairs Statistics Division. Population and vital statistics report. statistical papers series a vol. LXXII. New York, NY: United Nations, 2020. https://unstats.un.org/unsd/demographic-social/products/vitstats/

47 Sakamoto H, Rahman M, Nomura S, et al. Japan: Health system review. Health Systems in Transition. 8. New Delhi: World Health Organization, Regional Office for South-East Asia, 2018. https:// apps.who.int/iris/handle/10665/259941

48 OECD. OECD reviews of health care quality: Japan 2015: raising standards. Paris: OECD Publishing, 2015

49 Ministry of Health, Labour and Welfare. Patient safety Policiesexperiences, effects and priorities; lessons from OECD member states. Tokyo: Ministry of health, labour and welfare, 2018. Available: https://www.mhlw.go.jp/file/06-Seisakujouhou-10800000-Iseikyoku/ 0000204013.pdf [Accessed on 27 Feb 2020].

50 Kroneman M, Boerma W, van den Berg M, et al. Netherlands: Health system review. Health Systems in Transition, vol. 18 no. 2. World Health Organization, European Observatory on Health Systems and Policies, 2016. Available: http://www.euro.who.int/_data/assets/ pdf file/0016/314404/HIT_Netherlands.pdf?ua=1 [Accessed 26 Feb 2020].

$51 \AA$ A R, Sagan A, Saunes I. Health system in transition. 15. Norway: World Health Organization, European Observatory on Health Systems and Policies, 2013. http://www.euro.who.int/_data/assets/ pdf_file/0018/237204/HiT-Norway.pdf?ua=1

52 Chaufan C. Is the Swiss health care system a model for the United States? Int J Health Serv 2014;44:255-67.

53 Chastonay P, Simos J, Cantoreggi NL, et al. Health policy challenges in a decentralized federal state: the situation in Switzerland. $A R C J$ Public Health Community Med 2017;2:1-5.

54 Cylus J, Richardson E, Findley L, et al. United Kingdom: Health system review. Health Systems in Transition, vol. 17 no. 5. World Health Organization, European Observatory on Health Systems and Policies, 2015. Available: http://www.euro.who.int/_data/assets/pdf file/0006/302001/UK-HiT.pdf?ua=1 [Accessed 26 Feb 2020]. 